\title{
Hepatic fluorescence in porphyria cutanea tarda studied in fine needle aspiration biopsy smears
}

\author{
OVE LUNDVALL AND LENNART ENERBÄCK \\ From the Department of Medicine I, and the Department of Pathology I, \\ Sahlgren's Hospital, University of Göteborg, Göteborg, Sweden
}

SYNOPSIS Fine needle aspiration biopsy smears from 19 patients with porphyria cutanea tarda were studied by fluorescence microscopy. Fluorescence was arbitrarily graded from 0 to 4 . All patients -those with clinically manifest as well as those with latent disease-showed bright red fluorescence of porphyrin type in the liver cells, though in latent cases the fluorescence commonly was of a low grade. In patients with manifest disease fluorescence of grade 3 or 4 was present.

In patients with fluorescence of grades 1 or 2 the uroporphyrin excretion in urine was normal or slightly increased. At higher grades all levels of porphyrin excretion were encountered.

Of 22 control subjects, only one showed hepatic fluorescence of a porphyrin character. The control patient with a positive finding was found to have definitely increased urinary uroporphyrin excretion and probably has latent porphyria cutanea tarda.

The procedure described should be useful as a screening test for hepatic cutaneous porphyria.

Porphyria cutanea tarda symptomatica is clinically characterized by fragility of the skin and blisters on areas exposed to the sun. These frequently ulcerate and lead to scarring. Hypertrichosis and hyperpigmentation are common. The disease generally manifests itself in middle or later life. Males are much more commonly affected than females.

Chemically the disease is characterized by the excretion of large amounts of uroporphyrin and lesser amounts of coproporphyrin in the urine. The excretion of delta-aminolevulinic acid (ALA) may be slightly increased but the excretion of porphobilinogen is normal. The faecal excretion of coproporphyrin and of protoporphyrin is usually slightly increased.

The liver of patients with manifest porphyria cutanea tarda contains large amounts of preformed porphyrins, predominantly uroporphyrin (Schmid, Schwartz, and Watson, 1954), which emits a strong red autofluorescence in ultraviolet light. In some studies direct examination of liver biopsy specimens macroscopically under the ultraviolet light of a Wood's lamp consistently showed red fluorescence in patients with the disease (Braun, and Berman, 1959;

Received for publication 5 March 1969
Lamont, Hathorn, and Joubert, 1961; Uys and Eales, 1963). The diagnostic value of fluorescence microscopy of liver biopsy sections has been stressed (Niebauer, 1964) but the real results have been conflicting (Hickman, Saunders, and Eales, 1967; Uys and Eales, 1963), probably due to unsuitable histological methods (Uys and Eales, 1963).

In a study of various methodological, morphological, and quantitative aspects of liver cell fluorescence in porphyria cutanea tarda (Enerbäck, and Lundvall, 1969) we found that smears from fine needle aspiration biopsy specimens could be used for fluorescence microscopy study. This type of $N$ biopsy is easy to perform and can be done serially without undue risk if there is no bleeding tendency. We, therefore, studied a comparatively large number of patients by this method. We also studied the correlation between porphyrin excretion and hepatic 0 fluorescence intensity and between the clinical stage of the disease and fluorescence intensity.

\section{METHODS}

The biopsies were performed with the instrument designed by Franzén, Giertz, and Zajicek (1960). Long 
needles $(10-15 \mathrm{~cm})$ with an outer diameter of $0.7 \mathrm{~mm}$ are used. After local anaesthesia the puncture is performed in the mid-axillary line in a suitable intercostal space (usually the ninth) while the patient holds his breath. The needle is rapidly introduced through the liver parenchyma during continuous strong aspiration, which should be interrupted as soon as the tip of the needle has left the liver; if aspiration is maintained after the tip of the needle has left the skin the specimen will be lost into the syringe. The aspirate, consisting of blood, tissue fluid, tissue cells, and minute tissue particles, is immediately blown out on to a slide. The tiny drop is distributed on to several slides in thin short smears and allowed to dry in air. This technique has been described in detail by Söderström (1966).

The fluorescence microscopy examination was performed on the unfixed smears within a few hours after the biopsy. Fluorescence microscopy was performed with a Zeiss fluorescence microscope using an Osram HBO 200 high pressure mercury arc, equipped with a Schott BG 12 primary filter, as light source. The fluorescent light was filtered through a Zeiss $\mathbf{5 0}$ secondary filter transmitting above $500 \mathrm{~nm}$. Dark field condensers were used. For fluorescence photomicrographs Kodak high-speed Ektachrome films of daylight type or Kodak TriX films were used at exposure times of one half to 2 minutes.

The fluorescence was arbitrarily graded from 0 to 4 .

Urinary excretion of uroporphyrin and coproporphyrin was determined by the technique of Askevold (1951). To ensure conversion of precursor to coproporphyrin, an iodine wash according to the method of Watson, Pimenta de Mello, Schwartz, Hawkinson, and Bossenmaier (1951) was used. Quantitative determinations of coproporphyrin and protoporphyrin in faeces were made according to the method of Holti, Rimington, Tate, and Thomas (1958), using the formula given by Rimington and Sveinsson (1950) for the calculations. The extinction constants and corrections recommended by With (1955) were used. Quantitative urinary ALA and porphobilinogen determinations were performed according to the method of Mauzerall and Granick (1956).

The phlebotomy treatment, introduced by Ippen (1960), which in our series was consistently associated with clinical and partial biochemical remission, has been described elsewhere (Lundvall and Weinfeld, 1968).

\section{PATIENTS}

The control series comprised 22 alcoholics in whom biopsy was performed using thick and fine needles. Study on thick-needle biopsy sections revealed cirrhosis in two control patients. In the others steatosis was found in most cases. The porphyric series comprised 19 patients (Table I). Eight had typical clinical and biochemical signs of manifest porphyria cutanea tarda at the start of the study. Some of these were examined for hepatic porphyrin fluorescence before, during, and after phlebotomy at various stages of clinical activity. Eleven patients had the disorder clinically latent, but all had earlier had typical signs of manifest porphyria cutanea tarda. In eight of these clinical and partial biochemical remission had been induced by phlebotomy. Three patients had active disease some years before but had improved spontaneously.

\section{RESULTS}

With the technique described the smears macroscopically looked like bone marrow smears. Microscopically the hepatocytes were mainly found at the end of the smear, most occurring as small cell groups. At the end of the smears small lumps of liver tissue containing several layers of liver cells were seen. In controls the liver cells exhibited a dull green autofluorescence but the lumps of liver tissue fluoresced more brightly green. Blood cells fluoresced weakly green or not at all. In a few control specimens yellow or orange fluorescence of lipofuscin granules was seen. In small peripheral areas of the tissue lumps in control specimens a dull red colour sometimes appeared. Examination of these areas in transmitted light showed that they contained a layer of dried red blood cells, and this colour was quite different from the bright red fluorescence in specimens from porphyrics.

In specimens from control subjects no red autofluorescence of a porphyrin character was present except in those of one subject (grade 3). He was a 58-year-old alcoholic. He had never had skin symptoms. The urinary excretion of uroporphyrin was definitely increased $(0 \cdot 39-0 \cdot 37 \mathrm{mg} /$ day $)$ and was in the range of the patients with latent porphyria cutanea tarda. Urinary excretion of coproporphyrin and precursors was normal.

In all specimens from porphyric patients a bright red fluorescence was found. In specimens with strong or moderate intensity a diffuse red background was frequently observed. This was probably due to diffusion of porphyrins from liver cells. With growing experience it was found that a reproducible fluorescence quantitation into five grades could be achieved if both fluorescence intensity and distribution were taken into consideration (Enerbäck and Lundvall, 1969). The following grades were used: grade 0 , no fluorescence of porphyrin type; grade 1 , fluorescence of very weak intensity, confined to the nuclei of a minority of the hepatocytes, many tissue lumps showing exclusively green autofluorescence but in some smaller areas red fluorescence; grade 2, fluorescence of weak intensity in most hepatocytes confined to the nuclei, most tissue lumps showing areas with red fluorescence; grade 3 , fluorescence of moderate intensity, most hepatocytes showing fluorescence in the nuclei and many also in cytoplasm and the tissue lumps exhibiting red fluorescence mostly covering the green; grade 4, fluorescence of strong intensity, virtually all hepatocytes exhibiting red fluorescence in nuclei and cytoplasm 
and the bright red fluorescence of the tissue lumps completely covering the green.

The red fluorescence of the liver cells faded fairly rapidly during persistent illumination. In specimens with fluorescence of grade 1 to grade 3 the fluorescence was usually extinguished after one to two minutes' persistent illumination. Therefore only smears with the highest grade of fluorescence could be illuminated long enough for photomicrography. On the other hand the fading was never so strong as to interfere with the quantification of the fluorescence.

Fluorescent liver cells and a fluorescent lump of liver tissue are illustrated in Figures 1 and 2.

The results of the fluorescence grading and biochemical porphyrin analysis of the excreta of the patients with porphyria cutanea tarda are shown in Table I. Fluorescence of grades 3-4 was noted in all untreated patients. In four subjects the fluorescence was estimated before phlebotomy and during and/or after treatment. The fluorescence diminished from grade 3 to grade 1 in one patient (A.Go) and from grade 4 to grade 3 in two patients (O.I. and D.A.). In one (I.A.) the fluorescence increased from grade 3 to grade 4 during treatment. After further phlebotomies fluorescence of the pretreatment level (grade 3 ) was found and later on it diminished to grade 2.
The relation between clinical activity of the porphyric disease and fluorescence grading is shown in Figure 3. Patients with manifest disease had fluorescence of grades 3 to 4 . In patients with clinically latent disease grades 1 and 2 were most frequent but gradings of 3 to 4 were also encountered.

The relationship between fluorescence and urinary porphyrin excretion is shown in Figure 4. The uroporphyrin excretion in patients with fluorescence $\overrightarrow{0}$ of grades 1 to 2 was low (1.20 mg per day or less). $\vec{\overrightarrow{ }}$ In patients with grade 3 to 4 all levels of porphyrin $\vec{\omega}$ excretion were encountered.

\section{COMMENT}

The smears can be examined immediately after $\stackrel{\partial}{\circ}$ drying without further treatment. If mounting and cover glasses are preferred for optical reasons, watercontaining media such as buffered glycerol must be avoided since they cause a diffusion of the watersoluble porphyrins from the liver cells (Enerbäck and Lundvall, 1969).

With the present method all patients with porphyria cutanea tarda, those with clinically manifest as well $\overrightarrow{0}$ as those with clinically inactive disease, showed $\odot$ bright red fluorescence in the liver cells. It should be

TABLE I

FLUORESCENCE GRADING AND PORPHYRIN EXCRETION IN 19 PATIENTS WITH PORPHYRIA CUTANEA TARDA

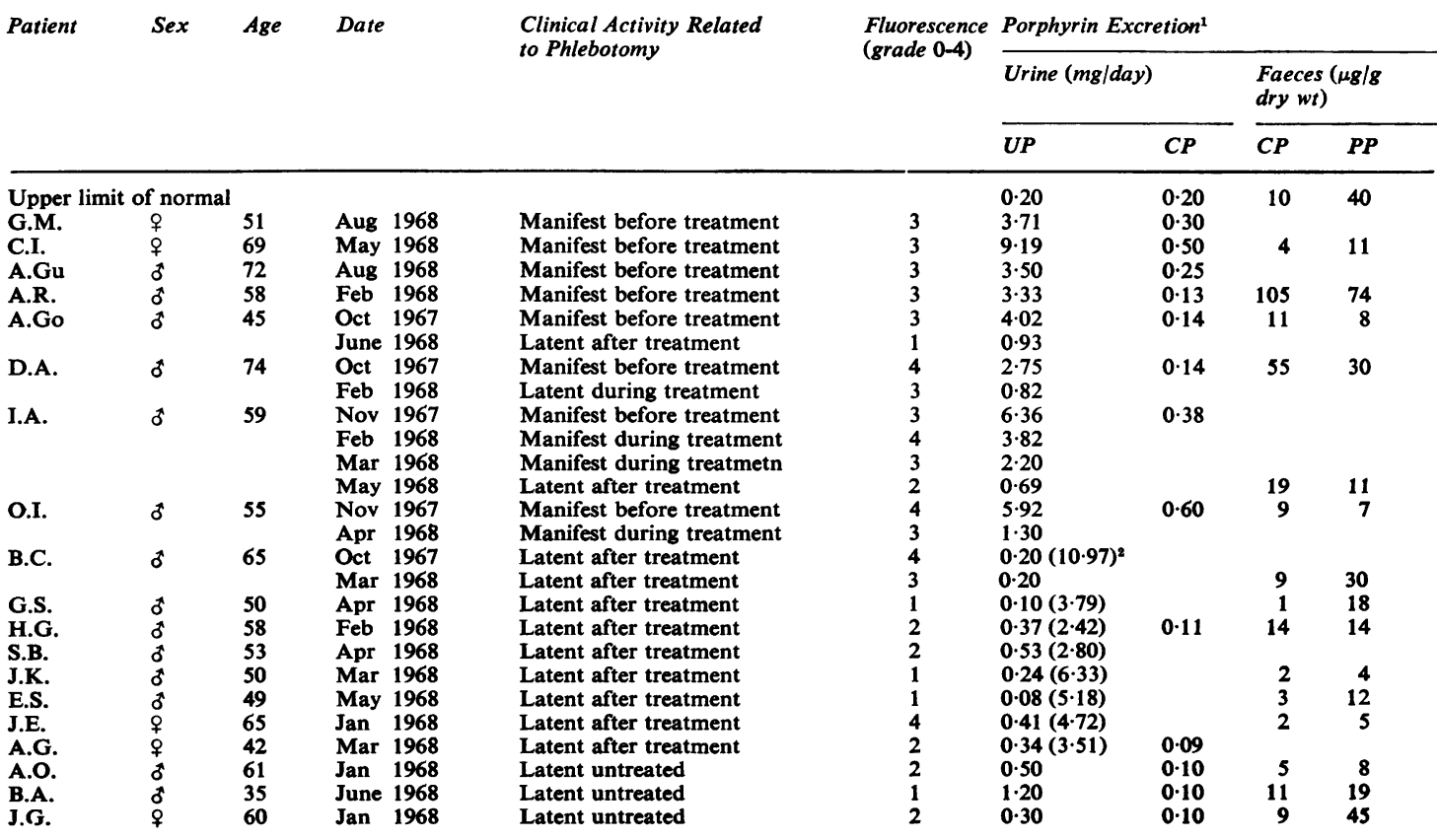

IUP= uroporphyrin; $\mathbf{C P}=$ coproporphyrin; $\mathbf{P P}=$ protoporphyrin

${ }^{2}$ Figures in brackets represent pretreatment values 


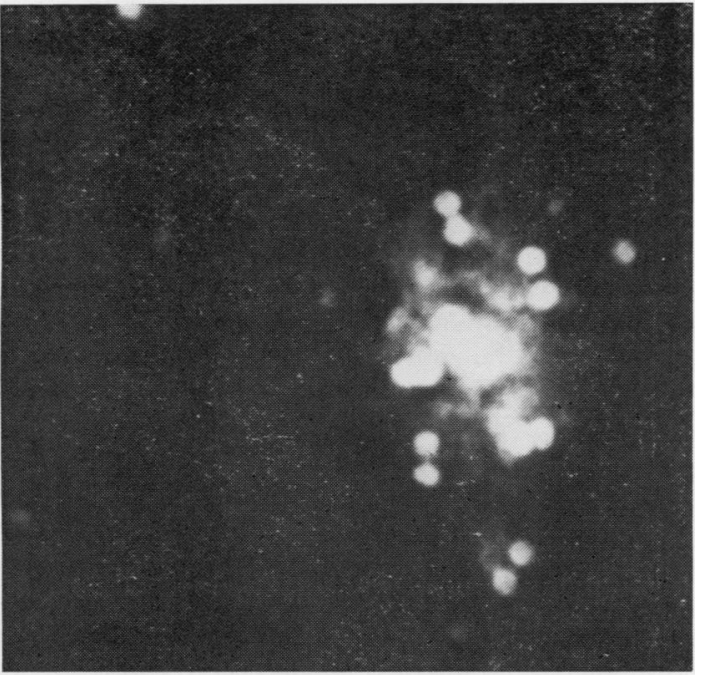

FIG. 1. Smear containing a group of liver cells with strong fluorescence both in cytoplasm and nuclei but of a higher intensity in the latter (grade 4) $\times 250$.

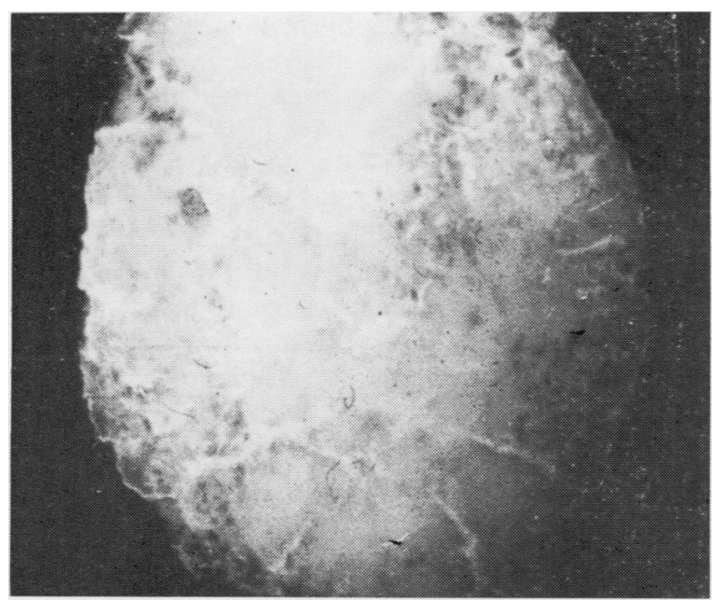

FIG. 2. Smear containing a lump of liver tissue with a homogeneous strong fluorescence (grade 4) $\times 250$.

pointed out, however, that the fluorescence of the liver cell nuclei is probably artifactive and due to diffusion of porphyrins from the cytoplasm (Enerbäck and Lundvall, 1969). The nuclear fluorescence is also present in thick needle biopsy sections but can be avoided by special precautions. Various attempts to avoid this diffusion in smears have been unsuccessful (Enerbäck and Lundvall, 1969), but diffusion does not discredit the method as a diagnostic tool. The method is easy to perform and there

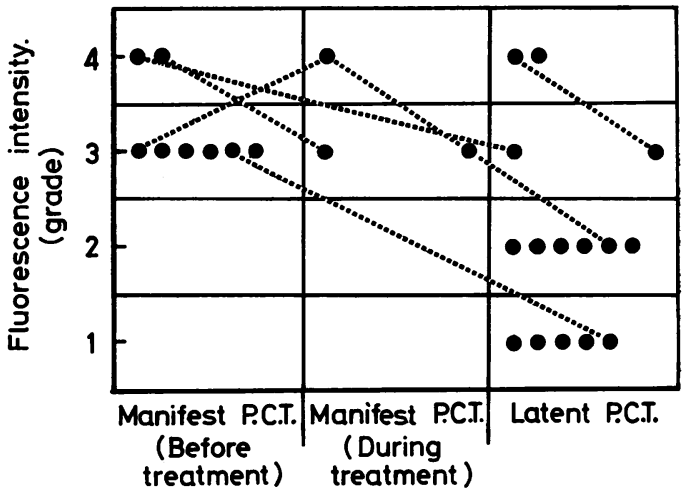

FIG. 3. Relation between clinical activity of the porphyric disease and grade of hepatic fluorescence. Determinations in one and the same patient are connected with dotted lines.

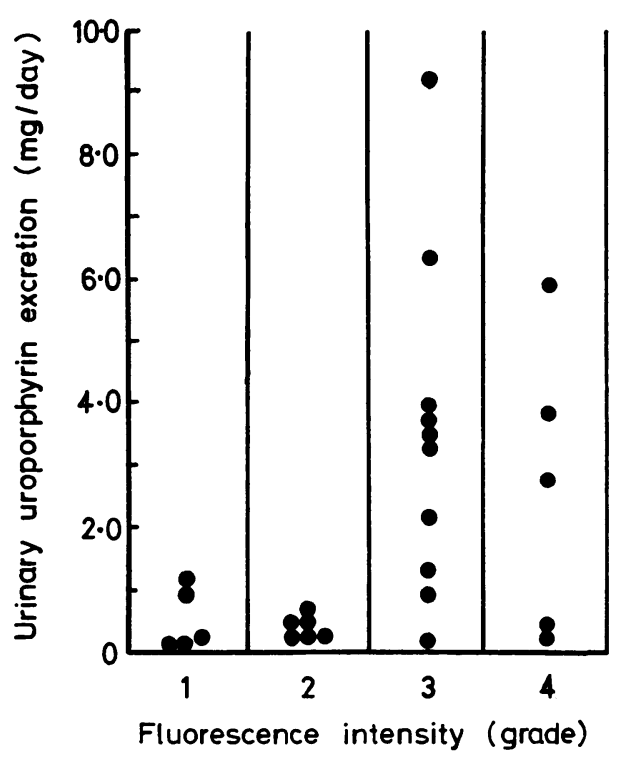

FIG. 4. Relation of urinary uroporphyrin excretion to the grade of fluorescence.

is no need to fix the smears. The more laborious method of histological biopsy sections requires specific precautions for reproducible results (Enerbäck and Lundvall, 1969; Grafflin, 1942) and probably explains the absence of porphyrin fluorescence in liver biopsy sections from patients with porphyria cutanea tarda in some studies (Hickman et al, 1967; Uys and Eales, 1963). Furthermore, conventional liver biopsy is not without risks. Using the fine needle biopsy technique,complications due to 
puncture are practically non-existent and the procedure described may be used as a screening test for hepatic cutaneous porphyria. The finding of bright red fluorescence in the liver indicates hepatic porphyria either of the present form or of the variegate form ('mixed' porphyria or South African genetic porphyria). In the last the liver also contains increased amounts of preformed porphyrins (Schmid et al, 1954). So far we have studied only one patient with the variegate form of hepatic porphyria; fluorescence of grade 2 was present. This patient had no clinical symptoms at the time of examination. In the differential diagnosis of hepatic cutaneous porphyria chemical analyses of urine and faeces should be performed. Urinary coproporphyrin and uroporphyrin may be increased in both conditions but in symptomatic porphyria cutanea tarda gross uroporphyrinuria is characteristic of the active phase. Urinary porphyrin may be normal in porphyria variegata but when raised coproporphyrin usually exceeds uroporphyrin. The faecal porphyrins in porphyria variegata are markedly increased, protoporphyrin usually exceeding coproporphyrin. In porphyria cutanea tarda coproporphyrin usually exceeds protoporphyrin. Furthermore, in porphyria variegata acute attacks of the same type as in porphyria acuta intermittens occur. During acute attacks the urinary excretion of porphyrin precursors is increased. In non-cutaneous hepatic porphyria (porphyria acuta intermittens) the liver contains increased amounts of precursors not giving rise to fluorescence. Weak hepatic fluorescence in occasional cases of this disease has, however, been reported (Schmid et al, 1954).

Patients with manifest disease had fluorescence of grades 3-4 and patients with latent disease usually had grades 1-2. In single patients with latent disease, however, fluorescence of the highest grades were encountered. In general, the fluorescence decreased in conjunction with phlebotomy (Fig. 3) but in one patient (I.A.) the fluorescence increased luring treatment. Differences in grading might be due to an uneven distribution of the fluorescence (Enerbäck and Lundvall, 1969). The distribution of the fluorescence in this patient (I.A.) was studied in specimens obtained from different depths of the liver. The fluorescence was equal in the smears from two depths, but was somewhat less at the third depth. We now introduce the needle as deeply as possible during aspiration in order to improve reproducibility. With thick needles material from such a large area cannot be obtained.

There is little information in the literature concerning the relationship between liver porphyrin concentration and urinary porphyrin excretion. In the paper by Schmid et al (1954) data on liver uropor- phyrin concentration and urinary uroporphyrin excretion in eight patients with porphyria cutanea tarda are available. In these few patients there was no significant correlation between urinary porphyrin excretion and liver uroporphyrin concentration. So $\overline{\frac{\bar{c}}{}}$ far we have not studied the relation between chemical uroporphyrin concentration in the liver and the grade of porphyrin fluorescence. The reproducibility $\infty$ of the grading is, however, good and the grading $\vec{O}$ method can be assumed to give a reasonably good measure of the porphyrin content of the liver $\stackrel{\sigma}{\sigma}$ (Enerbäck and Lundvall, 1969). In the present series there was a relationship between the liver fluorescence and urinary porphyrin excretion; the mean uro- ? porphyrin excretion of those with fluorescence of grades 1-2 was significantly lower than that of those with grades 3-4. Though fluorescence of grades 1-2 was 응 always associated with low uroporphyrin excretion $(0 \cdot 08-1 \cdot 20 \mathrm{mg} / 24 \mathrm{hr})$ grades 3-4 were compatible with $z$ both low and high uroporphyrin excretion (0.20$9 \cdot 19 \mathrm{mg}$ ). It is probable that the rate of uroporphyrin excretion in urine is conditioned by the rate of uroporphyrin production and by the capacity of the liver to store porphyrin. It is conceivable that urinary uroporphyrin excretion is low until the capacity of the liver to store uroporphyrin is surpassed. If so, the estimation of hepatic fluorescence might be a more sensible diagnostic measure than routine chemical analysis of porphyrins in urine and faeces. This view is supported by the fact that two patients $\stackrel{\mathbb{D}}{\AA}$ with latent porphyria cutanea tarda (after phlebotomy treatment) had red fluorescence in liver cells in spite of quantitatively normal porphyrin excretion.

Fluorescence of grade 3 was found in one control subject. He had, however, biochemical findings compatible with latent porphyria cutanea tarda. In no other control patient was red fluorescence observed, but in single specimens yellow or orange fluorescence of lipofuscin granules was seen. These can, however, easily be identified because of their characteristic appearance.

In the periphery of the tissue lumps a zone of dull $\rightarrow$ red fluorescence was sometimes observed, and examination in transmitted light revealed that it was $N$ composed of a layer of dried red blood cells. This colour was quite different from the bright red colour of the porphyrin fluorescence and was probably due $\omega$ to an absorption quenching of the tissue autofluorescence caused by the red blood cells (Enerbäck $\varrho$ and Lundvall, 1969).

Many drugs concentrate in the liver cells. So far, we do not know of any drug giving red fluorescence. Fluorescence in livers from subjects treated with drugs with unknown fluorescence properties should, $\cong$ however, be evaluated with the possibility of druginduced fluorescence in mind. 


\section{REFERENCES}

Askevold, R. (1951). Scand. J. clin. Lab. Invest., 3, 318.

Braun, A., and Berman, J. (1959). Acta Univ. Carol. Med. (Praha), 5, 597.

Enerbäck, L., and Lundvall, O. (1969). To be published.

Franzén, S., Giertz, G., and Zajicek, J. (1960). Brit. J. Urol., 32, 193.

Grafflin, A. L. (1942). Amer. J. Anat., 71, 43.

Hickman, R., Saunders, S. J., and Eales, L. (1967). S. Afr. med. J., 41, 456.

Holti, G., Rimington, C., Tate, B. C., and Thomas, G. (1958). Quart. J. Med., 27, 1.

Ippen, H. (1960). Klin. Wschr., 38, 89.

Lamont, N. M., Hathorn, M., and Joubert, S. M. (1961). Quart. J. Med., 30, 373.
Lundvall, O., and Weinfeld, A. (1968). Acta med. scand., 184, 191. Mauzerall, D., and Granick, S. (1956). J. biol. Chem., 219, 435.

Niebauer, C. (1964). Arch. klin. exp. Derm., 219, 738.

Rimington, C., and Sveinsson, S. L. (1950). Scand. J. clin. Lab. Invest., 2, 209.

Schmid, R., Schwartz, S., and Watson, C. J. (1954). Arch. intern. Med., 93, 167.

Söderström, N. (1966). Fine-Needle Aspiration Biopsy. Almqvist and Wiksell, Stockholm.

Uys, C. J., and Eales, L. (1963). S. Afr. J. Lab. clin. Med., 9, 190.

Watson, C. J., Pimenta de Mello, R., Schwartz, S., Hawkinson, V. E., and Bossenmaier, I. (1951). J. Lab. clin. Med., 37, 831.

With, T. K. (1955). Scand. J. clin. Lab. Invest., 7, 193.

\section{The November 1969 Issue}

\section{THE NOVEMBER 1969 ISSUE CONTAINS THE FOLLOWING PAPERS}

$Q$ fever and leptospirosis in the dairy farming community and allied workers of Worcestershire R. J. HENDERSON

Influence of various parameters on the sensitivity of precipitin tests in farmer's lung by immunodiffusion and immunoosmophoresis J. E. JAMESON

Precipitins with relevance to farmer's lung and aspergillosis in normal and other sera J. E. JAMESON

A modified test for Brucella agglutinins J. N. SINGH

Modification of the indirect haemagglutination test for amoebiasis IRIS M. KRUPP

Effect of medium composition on the apparent sensitivity of Pseudomonas aeruginosa to gentamicin L. P. GARROD and PAMELA M. WATERWORTH

Peritoneal infections in patients on long-term peritoneal dialysis before and after human cadaveric renal transplantation D. A. LEIGH

Patterns of plasma cobalamins in control subjects and in cases of vitamin $B_{12}$ deficiency J. C. LINNELL, HEATHER $M$. MACKENZIE, J. WILSON, and D. M. MATTHEWS

Effect of vitamin $B_{12}$ and folic acid deficiency on small intestinal absorption JOHN FORSHAW

Effect of antimicrobial agents on the Euglena method of serum vitamin $B_{12}$ assay J. T. LIE, BERTA UNGAR, and D. C. COWLING

Quantitation of lymphocyte transformation using radioactive iododeoxyuridine A. W. CRAIG, J. V. GARRETT, and S. M. JACKSON

Relationship of platelet retention in glass bead columns to the rate of aggregation with adenosine diphosphate and thrombin A. L. BLOOM and E. P. EVANS

Quantitative enzyme cytochemistry of leukaemic cells J. STUART, LUCILLE BITENSKY, and J. CHAYEN
Transfusional siderosis and liver cirrhosis R. SINNIAH

Recent views on Buerger's disease GEORGE WILLIAMS

Fine structural appearances of glomerular capillaries in a case of malignant hypertension R. F. MACADAM

Chemodectoma of the orbit A. AHMED, O. G. DODGE, and R. S. KIRK

Application of standard micro-anatomical staining methods to epoxy resin-embedded sections S. R. APARICIO and P. MARSDEN

Vaginal fluid enzyme patterns in benign and malignant lesions of the female genital tract G. G. MUIR and G. VALTERIS

Plasma 'cortisol' levels in right and left ventricular failure C. K. CONNOLLY and M. R. WILLS

Detection of methaqualone and its metabolites in urine D. BURNETT, J. H. GOUDIE, and J. MUNRO SHERRIFF

Semi-automated micromethod for estimating the unsaturated iron-binding capacity of serum using radioactive iron B. BROZOVICH and J. COPESTAKE

On-line acquisition of the output of AutoAnalyzers P. D. GRIFFITHS and N. W. CARTER

Work study of a desk computer in the clinical laboratory J. G. LINES

\section{Technical methods}

Modification of the method for the estimation of xylose in urine J. M. GOODHART and GWENDOLINE R. KINGSTON

Simplified apparatus for ultrafiltration by centrifugation M. R. LEWIN

Letters to the Editor

Book reviews/Notices

Copies are still available and may be obtained from the PUBLISHING MANAGER, BRITISH MEDICAL ASSOCIATION, TAVISTOCK SQUARE, W.C.1 price $21 \mathrm{~s}$. 